\title{
Cruciform specimens for the determination of crack growth behaviour in biaxial stress fields: calculation of $K$-factors
}

\author{
Carl H. Wolf ${ }^{1, *}$, Andreas Burgold ${ }^{2}$, Sebastian Henkel ${ }^{1}$, Meinhard $\mathrm{Kuna}^{2}$, and Horst \\ Biermann $^{1}$ \\ ${ }^{1}$ Institute of Materials Engineering, Technische Universität Bergakademie Freiberg, Gustav-Zeuner- \\ Str. 5, 09599 Freiberg, Germany \\ ${ }^{2}$ Institute of Mechanics and Fluid Dynamics, Technische Universität Bergakademie Freiberg, Lampa- \\ diusstraße 4, 09599 Freiberg, Germany
}

\begin{abstract}
The aim of this study is to propose a simplified calculation of the Mode I stress intensity factor $K$ for the cruciform specimen design proposed by Brown and Miller. To calculate $K$, both cracks have to grow with a similar crack growth rate and the crack paths of the two single cracks with the length $a$ should also be similar. The calculations are carried out on an aluminum specimen and a steel specimen. For all load cases and materials, the stresses resulting from the forces are first considered. It was found that the elastic constants $E$ and $v$ have only a small influence of less than $3 \%$. In addition, the coupling between the forces of the load axes, which should be minimized by the slotted arms, is considered. Furthermore $K$-factors are calculated by $\mathrm{FE}$ for different crack lengths. These $K$-values together with the transmission factor allow to find a $K$-factor formula for cruciform specimens, which is based on the prescribed forces. Finally, the results of the FE calculation of the exact straight crack paths were compared to experimentally determined crack paths.
\end{abstract}

\section{Introduction}

Many components are subjected to multi-axial stress conditions during their service life. However, the estimation of fatigue crack growth is often based on uniaxial data. In addition, biaxial fatigue crack growth investigations are an important link between the uniaxial small-scale tests on the one hand and the complex component tests on the other hand. Difficulties in investigating fatigue crack growth under planar biaxial loading arise from the different specimen types, as there are many different testing machines and no standardized specimen design. However, three common specimen designs can be found in the literature:

(i) flat specimen design with large radii between the loading arms, see e.g. Refs. [1, 2],

(ii) flat specimen design with small radii between the loading arms, see e.g. Refs. [3-7], and

(iii) specimen design with thickness-reduced measuring area and slotted arms, see e.g. Refs. [7-17].

As a result of the different specimen designs, the $K$-solution has to be computed for each specimen design by FE-calculations considering the individual crack paths and the material.

\footnotetext{
*e-mail: Carl.Wolf@ww.tu-freiberg.de
} 
Thus, different evaluations of the crack growth rate are made in the literature for cruciform specimens, for example

(i) only evaluation of crack length $a$ and number of load cycles $N$, see e.g. Ref. [4],

(ii) evaluation of the crack growth rate $d a / d N$ versus the number of load cycles $N$, see e.g. Ref. [8], and

(iii) evaluation of the crack growth rate $d a / d N$ versus the stress intensity factor $K$ or rather its range $\Delta K$, see e.g. Refs. [1-3, 6, 7, 10-16, 18, 19].

Causes for these different approaches are among other things the mutual influence of the individual crack paths within the studies specimens, which makes a FE calculation of the entire specimen necessary for each crack length $a$, as soon as the crack paths of the individual cracks differ from each other or are not symmetrical. Furthermore, the determination of the resulting stress intensity at the crack tip is more complex due to the component geometry and the biaxial loading compared to uniaxial loaded specimens.

The aim of the present investigation is first to analyse the stress distribution of the specimens used in recent works (cf. e.g. Refs. [14, 15, 20, 21]). Subsequently, a simple model is developed to calculate the stress intensity factors for straight crack paths that grow parallel to one loading axis or with an angle of $45^{\circ}$ to both load axes.

\section{Material and methods}

\subsection{Materials}

The experimental investigations were performed on a powder metallurgically produced austenitic stainless steel X5CrMnNi16-7-7, called „PM“ in the following. In recent work, the aluminum alloy EN AW-AlMgSi1Cu in the condition T651, i. e. solution annealed, quenched, controlled strained and artificially aged, called „A16061“ in the following, has also been investigated, see e.g. Refs. [14, 20,21]. The chemical composition of both materials can be found in Ref. [21]. The stress-strain curves and selected mechanical properties of the investigated materials are given in Fig. 1. Further mechanical properties can be found in Refs. [14, 15, 21]

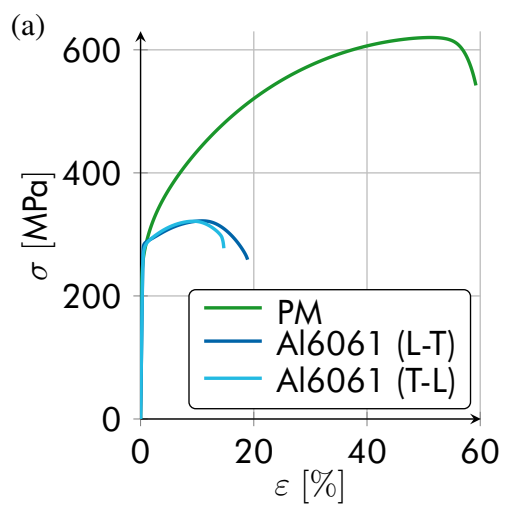

(b)

\begin{tabular}{lrrr}
\hline material & $\begin{array}{r}\mathrm{R}_{\mathrm{p} 0,2} \\
{[\mathrm{MPa}]}\end{array}$ & $\begin{array}{c}\mathrm{R}_{\mathrm{m}} \\
{[\mathrm{MPa}]}\end{array}$ & $\begin{array}{c}\mathrm{A}_{5} \\
{[\%]}\end{array}$ \\
\hline PM & 252 & 624 & 60 \\
\hline Al6061 (L-T) & 282 & 319 & 18.1 \\
Al6061 (T-L) & 275 & 321 & 14.5 \\
Standard* $^{*}$ & 240 & 290 & 9.0 \\
\hline
\end{tabular}

${ }^{*}$ Minimum values according to DIN EN 485-2 for plates with a thickness of $6 \mathrm{~mm}$ to $12 \mathrm{~mm}$.

\subsection{Specimens}

The design of the examined cruciform specimens, see Fig. 2, corresponds to that of Brown and Miller [10]. Their measuring area is reduced in thickness and has a length of 
$W=130.8 \mathrm{~mm}$, see Fig. 2b. The load application arms are slotted in order to achieve uncoupling of the forces of the two loading axes, see Ref. [22]. A hole with a diameter of $d=4 \mathrm{~mm}$ was first drilled in the middle of the measuring area. Subsequently two start notches were inserted by electro discharge machining and served as initial crack starter. These notches have a length of $2 a=10 \mathrm{~mm}$, i.e. each crack has a length of $a=5 \mathrm{~mm}$ at the beginning of the investigation. They represent a central through crack in a large plate of small thickness (see e.g. Ref. [23]).

Depending on the alignment of notches, a large number of tests can be carried out. If the start notches are aligned parallel to one loading axis, the specimen is called „, $0^{\circ}$-specimen“ in the following, see Fig. 2a. This specimen design can be used for investigations on the influence of the T-stress, see e.g. Ref. [20]. If the notches are aligned at an angle of $45^{\circ}$ to both load axes, the specimen is called „ $45^{\circ}$-specimen“ in the following, see Fig. 2 b. This specimen design can be used to carry out both equibiaxially loaded tests without T-stress [24] and tests with phase-shifted loadings.
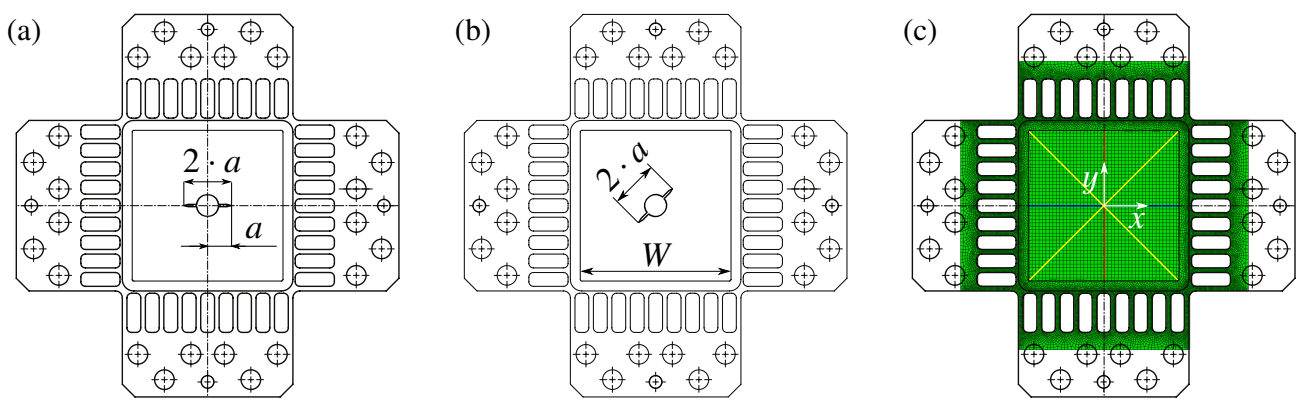

Figure 2. Design of the cruciform specimens: (a) Specimen with centered notch aligned parallel to one loading axis $\left(0^{\circ}\right.$-specimen), (b) specimen with centered notch aligned with an angle of $\alpha=45^{\circ}$ to both loading axes ( $45^{\circ}$-specimen) and (c) uncracked specimen showing the mesh of the FE calculation as well as considered crack paths.

\subsection{Testing system}

The tests were performed on a servo-hydraulic, planar-biaxial tension-compression testing system with two perpendicular loading axes in force-controlled mode and a test frequency of $f=20 \mathrm{~Hz}$. The loading function was sinusoidal.

Parallel to the front side of the specimen, a high-resolution camera system with a measuring area of $118.8 \mathrm{~mm} \times 118.8 \mathrm{~mm}$ was positioned. The images were recorded during the entire experiment in intervals of 1500 to 10000 load cycles and were taken at mean stress. For this purpose the experiment had to be interrupted. When the experiment was finished, the cracks were measured using the image processing system ImageJ according to Ref. [9]. The determined crack tip coordinates were used for the FE calculation. Furthermore, FE calculations were performed for ideally straight crack paths for the $0^{\circ}$-specimens, see Fig. $2 \mathrm{a}$, and $45^{\circ}$-specimens, see Fig. 2b, for PM and Al6061.

In addition, the crack length was measured using crack gages (Krak Gage B 20). These were applied to both notches on the specimen surface. The actual crack length was measured by the indirect potential method using the RUMUL FRACTOMAT from Russenberger Prüfmaschinen AG (Neuhausen am Rheinfall, Switzerland). 


\subsection{Forces, stresses and stress intensity factors}

\subsubsection{Scaling of the forces, stresses and stress intensity factors}

The analysis of the specimen by means of the concept of linear elasticity allows a scaling of the forces and stresses, i.e. the FE calculations have been performed with unit forces of $f_{x}=1 \mathrm{kN}$ or $f_{y}=1 \mathrm{kN}$, see Ref. [15]. The unit forces can be scaled by scaling factors $b_{x}$ or $b_{y}$ to the experimental forces $F_{x}$ or $F_{y}$, see Eq. (1).

$$
F_{i}=f_{i} \cdot b_{i} \quad i \in[x, y]
$$

Also, the resulting sectional stress distributions $\sigma_{i}$ at the crack location (without crack) can be scaled by the factor $b_{i}$ from unit stresses $s_{i}$, see Eq.(2).

$$
\sigma_{i}=s_{i} \cdot b_{i} \quad i \in[x, y]
$$

Furthermore, a scaling of the unit Mode I stress intensity factors $k_{i}$ determined by FE is possible up to the resulting stress intensity factors $K_{x}$ or $K_{y}$, see Eq. (3).

$$
K_{i}=k_{i} \cdot b_{i} \quad i \in[x, y]
$$

The stress intensity factor for a thin plate of infinite size $K_{\infty}$ can be described by Eq. (4). For the calculation of $K_{\infty}$, see Eq. (4), the stress $\sigma$ is the stress perpendicular to the crack plane in the center of the uncracked cruciform specimen. The determination of the stress intensity factors for other specimen geometries as well as components $K_{\text {comp }}$ is performed by means of the crack length-dependent as well as geometry-dependent correction function $Y(a)$, see Eq. (5). The determination of the $Y$ values for specific crack length $a$ for cruciform specimens can by done by Eq. (6).

$$
\begin{aligned}
K_{\infty} & =\sigma \cdot \sqrt{\pi \cdot a} \\
K_{\mathrm{comp}} & =\sigma \cdot \sqrt{\pi \cdot a} \cdot Y(a) \\
Y_{i}(a) & =\frac{K_{i}}{K_{\infty}}=\frac{k_{i}}{k_{\infty}} \quad i \in[x, y]
\end{aligned}
$$

For simplification, the $k_{x}, k_{y}$ and $k_{\infty}$ values for certain crack length $a$ have to be calculated. Subsequently, the $Y_{x}(a)$ or $Y_{y}(a)$ values for certain crack length $a$ have to be calculated using Eq. (6). Afterwards, using a polynomial fit for $Y_{x}(a)$ or $Y_{y}(a)$, the $Y_{x}(a)$ or $Y_{y}(a)$ have to be interpolated for the crack length in the range of used crack length values. Finally, the stress intensity factors for the cruciform specimens $K_{\mathrm{CS}}$ can be calculated by Eq. (7) using the determined correction functions.

$$
K_{\mathrm{CS}}=\left[\sigma_{x} \cdot Y_{x}(a)+\sigma_{y} \cdot Y_{y}(a)\right] \cdot \sqrt{\pi \cdot a}
$$

In dependence of the alignment of the start notches, see Figs. $2 \mathrm{a}\left(0^{\circ}\right.$-specimen $)$ and $2 \mathrm{~b}\left(45^{\circ}\right.$ specimen), and the resulting crack growth direction, some simplifications can be made. This will be described below.

\subsection{2 $0^{\circ}$-specimen with static loading in $x$-direction and cyclic loading in $y$-direction}

\section{Calculation of the cyclic stress intensity factor}

The stress intensity factor for $0^{\circ}$-specimens (cf. Fig. 2a) has to be calculated using Eq. (7) due to the possible different amount of forces $F_{x}$ and $F_{y}$ and stresses $\sigma_{x}$ and $\sigma_{y}$, respectively. The direction-dependent values of $K_{i}$ can be determined using Eq. (8) and the cyclic stress intensity factor $\Delta K$ is defined by Eq. (9).

$$
\begin{aligned}
K_{i} & =\sigma_{i} \cdot \sqrt{\pi \cdot a} \cdot Y_{i}(a) \quad i \in[x, y] \\
\Delta K & =K_{\max }-K_{\min }
\end{aligned}
$$


However, there is the possibility of simplification in the case of cyclic loading in the $y$ direction and static loading in the $x$-direction. Due to a constant force $F_{x}$ in $x$-direction, the stress intensity factors $K_{\min , x}$ and $K_{\max , x}$ are equal, i.e. $K_{x}=K_{\min , x}=K_{\max , x}=$ constant, and therefore $\Delta K_{x}=0$. Because of this simplification, the cyclic stress intensity factor for $0^{\circ}$-specimens with static loading in $x$-direction and cyclic loading in $y$-direction $\Delta K_{\mathrm{CS}}^{0^{\circ}}$ is obtained using Eq. (10). Finally, by inserting Eq. (8) in Eq. (10), $\Delta K_{\mathrm{CS}}^{0^{\circ}}$ can be calculated using Eq. (11).

$$
\begin{aligned}
& \Delta K_{\mathrm{CS}}^{0^{\circ}}=\left(K_{x}+K_{\max , y}\right)-\left(K_{x}+K_{\min , y}\right)=K_{\max , y}-K_{\min , y} \\
& \Delta K_{\mathrm{CS}}^{0^{\circ}}=\left(\sigma_{\max , y}-\sigma_{\min , y}\right) \cdot \sqrt{\pi \cdot a} \cdot Y_{y}(a)=\Delta \sigma_{y} \cdot \sqrt{\pi \cdot a} \cdot Y_{y}(a)
\end{aligned}
$$

\section{Experimental loading}

The experiment was performed with a specimen made of PM. Two different $R$-ratios have been tested. The mean forces were $F_{m, y}=29.14 \mathrm{kN}$ for $R=0.1$ and $F_{m, y}=39.68 \mathrm{kN}$ for $R=0.5$. The force amplitudes were $F_{a, y}=23.76 \mathrm{kN}$ for $R=0.1$ and $F_{a, y}=13.23 \mathrm{kN}$ for $R=0.5$. The details of test conditions were given in a recent work, see Ref. [21].

\subsubsection{Equibiaxially loaded $45^{\circ}$-specimen}

\section{Calculation of the cyclic stress intensity factor}

Due to equal and synchronous forces in $x$ and $y$ direction in the case of equibiaxial loading, i.e. $F_{x}=F_{y}$, a simplification of Eq. (7) can be done to calculate the stress intensity factor for static $K_{\mathrm{CS}}^{45^{\circ}}$ as well as cyclic loading $\Delta K_{\mathrm{CS}}^{45^{\circ}}$ for $45^{\circ}$-specimens, see Eqs. (12) or (13).

$$
\begin{aligned}
K_{\mathrm{CS}}^{45^{\circ}} & =K_{x}+K_{y}=\left(\sigma_{x}+\sigma_{y}\right) \cdot \sqrt{\pi \cdot a} \cdot Y(a)=\left(s_{x}+s_{y}\right) \cdot b \cdot \sqrt{\pi \cdot a} \cdot Y(a) \\
\Delta K_{\mathrm{CS}}^{45^{\circ}} & =\left(s_{x}+s_{y}\right) \cdot \Delta b \cdot \sqrt{\pi \cdot a} \cdot Y(a)
\end{aligned}
$$

Due to symmetry, the shear opening Modes II cancel each other, such that a pure Mode I occurs. This means, also a simplification of Eq. (6) can be made. Finally, only one correction function $Y(a)$ is necessary and can be calculated using Eq. (14).

$$
Y(a)=\frac{\left(K_{x}+K_{y}\right)}{K_{\infty}}=\frac{\left(k_{x}+k_{y}\right)}{\left(s_{x}+s_{y}\right) \cdot \sqrt{\pi \cdot a}}
$$

\section{Experimental loading}

The experiment was performed with a specimen made of PM. The mean forces were $F_{m, x}=F_{m, y}=29.14 \mathrm{kN}$. The force amplitudes were $F_{a, x}=F_{a, y}=23.76 \mathrm{kN}$. The complete test conditions were given in a recent work, see Ref. [21].

\subsection{FE calculations}

The determination of a material-dependent $K$-solution for cruciform specimens with straight crack path is carried out with the results of the FE calculation of both materials. The FE calculation is based on the material parameters Young's modulus $E=192 \mathrm{GPa}$ and Poisson's ratio $v=0.24$ for $\mathrm{PM}$ and $E=72 \mathrm{GPa}$ and $v=0.34$ for Al6061, respectively.

In order to compute the geometry functions $Y_{i}(a)$, see Eq. (6), there are several quantities, which have to be calculated with finite elements. On the one hand, the stress distribution in the center of the cruciform specimen without crack is needed $\left(s_{x}\right.$ and $s_{y}$ or rather $\sigma_{x}$ and $\sigma_{y}$ ) in the $K$-formulas, see Eqs. (5) and (7), and in the reference solution $K_{\infty}$, see Eq. (4). 
On the other hand, $k$-factors, see Eq. (6), are evaluated for different crack lengths and crack configurations, see Figs. $2 \mathrm{a}$ and $2 \mathrm{~b}$.

The 2D finite element analyses were carried with the commercial software ABAQUS. Plane stress conditions are assumed. The material behavior is modeled as linear elastic. For all computations fully integrated quadrilateral elements with quadratic shape functions (8 nodes, 9 integration points) are used. Unit forces $f_{x}=1 \mathrm{kN}$ or $f_{y}=1 \mathrm{kN}$ are considered.

The mesh of a cruciform specimen without hole and crack is shown in Fig. 2c. In the next step stress components are evaluated along the paths market in this figure. They are used for superposition in order to determine the stress state in the center of the specimen under given external loading conditions. Furthermore, stress intensity factors are computed by the ABAQUS built-in interaction integral technique for numerous cracked configurations.

\section{Results and Discussion}

\subsection{Stress distribution in the uncracked specimen}

The stresses resulting from the load with the unit force or forces, respectively, are shown in Fig. 3. This figure shows only the stress distribution for PM. The stress distribution for Al6061 was shown in a recent work, see Ref. [20]. The colors of the different lines in Figs. 3a to $3 \mathrm{~d}$ correspond to the colours of the lines in Fig. 2c. The stresses along the diagonals (cf. Fig. 2c, yellow lines) need to be calculated only along one diagonal due to the symmetry of the specimen.

Fig. 3 a shows the resulting stresses in $x$-direction $s_{x}$ along the respective crack sections at a static unit force in $y$-direction of $f_{y}=1 \mathrm{kN}$. In the middle of the specimen and along the diagonals, compressive stresses arise, whereas tensile stresses occur at the edges of the $x$ and $y$-axes. The compressive stress in the middle of the specimen is $s_{x}=0.062 \mathrm{MPa}$ for PM and $s_{x}=0.0362 \mathrm{MPa}$ for Al6061.

The resulting stresses in $y$-direction $s_{y}$ at a static unit force in $y$-direction of $f_{y}=1 \mathrm{kN}$ are shown in Fig. 3b. It becomes clear that tensile stresses occur over the entire cross-section of the specimen. The tensile stress in the middle of the specimen is $s_{y}=2.933 \mathrm{MPa}$ for PM and $s_{y}=2.948 \mathrm{MPa}$ for A16061. No shear stresses $\tau_{x y}$ occur in these cases.

Due to the symmetry of the unnotched specimen, the amount of the resulting stress $s_{y}$ at a force of $f_{y}=1 \mathrm{kN}$ is equal to the resulting stress $s_{x}$ at a force of $f_{x}=1 \mathrm{kN}$. The stresses $s_{x}$ at $f_{y}=1 \mathrm{kN}$ and $s_{y}$ at $f_{x}=1 \mathrm{kN}$ are also identical. Thus the resulting stresses for equibiaxial loading can be calculated for the given cross-sections, see Fig. 3c. It becomes clear that the stress distribution is more homogeneous compared to the uniaxial loading, compare Fig. $3 \mathrm{c}$ with Figs. $3 \mathrm{a}$ and $3 \mathrm{~b}$. The resulting stress in the middle of the equibiaxially loaded, unnotched specimen is $s_{x}=s_{y}=2.871 \mathrm{MPa}$ for PM and $s_{x}=s_{y}=2.912 \mathrm{MPa}$ for Al6061. The coupling of the forces, as also described in Ref. [22], is less than $3 \%$ for both materials in the middle of the specimen, see Fig. 3d and Ref. [20]. It becomes clear that despite of differences in Young's modulus and in Poisson's ratio of both materials, the resulting stresses are very close. For the calculation of an approximate material-independent solution of the correction functions $Y^{\text {fit }}(a)$ or $Y_{y}^{\text {fit }}(a)$, the mean values of the stresses are therefore used in the following, i.e. $s_{x}=-0.05 \mathrm{MPa}$ and $s_{y}=2.94 \mathrm{MPa}$.

\subsection{Correction functions and stress intensity factors}

First, the correction functions $Y^{\mathrm{fit}}(a)$ or $Y_{y}^{\mathrm{fit}}(a)$ were calculated. Fig. 4 shows the materialindependent solution of these correction functions. The fit function for the $0^{\circ}$-specimen with static loading in $x$-direction and cyclic loading in $y$-direction in Fig. 4a is given in Eq. (15). 
(a)

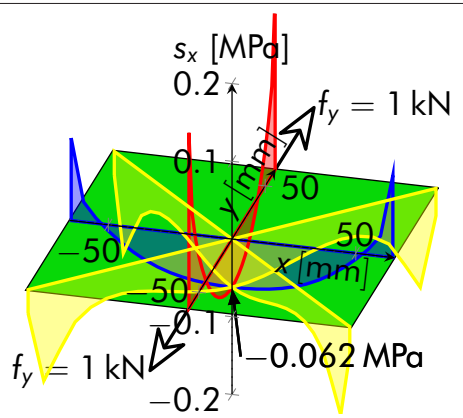

(c)

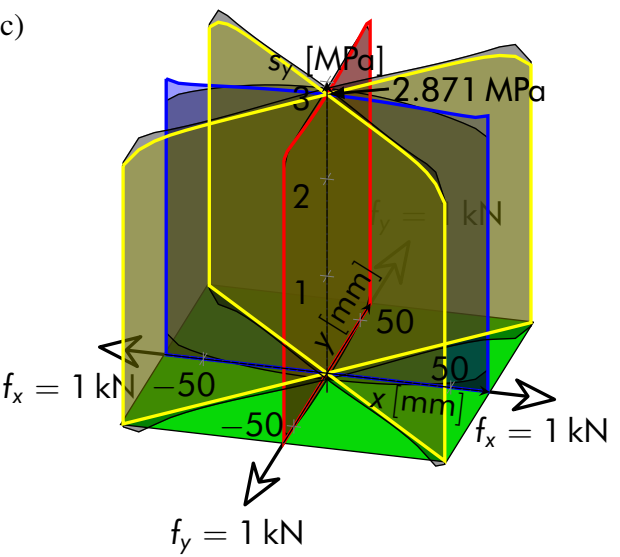

(b)

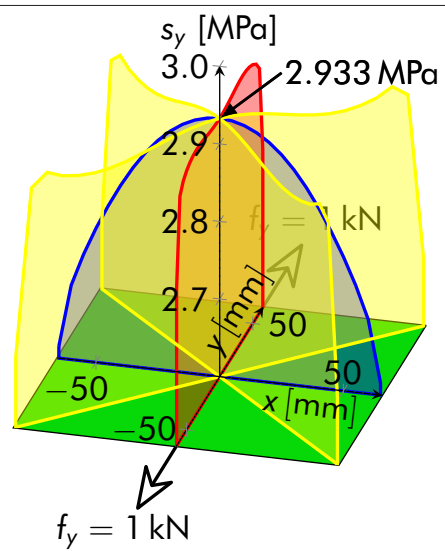

(d)

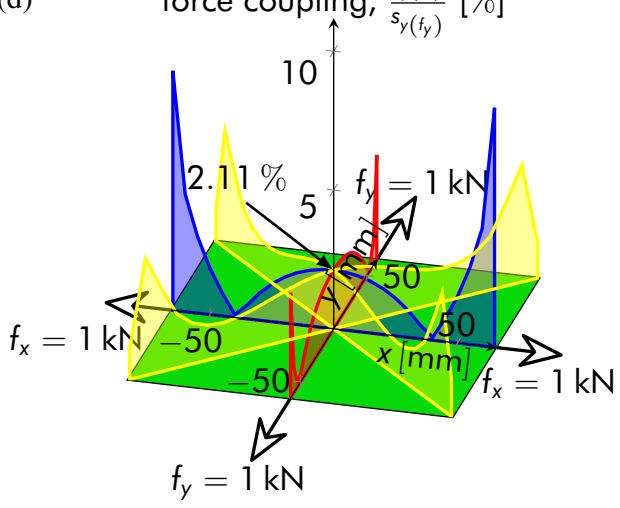

Figure 3. Resulting stresses in the specimen along the $x$-axis (cf. Fig. 2c, blue line), $y$-axis (cf. Fig. 2c, red line), and diagonal (cf. Fig. 2c, yellow line). (a) Resulting stresses in $x$-direction $s_{x}$ at a tensile force in $y$-direction of $f_{y}=1 \mathrm{kN}$. (b) Resulting stresses in $y$-direction $s_{y}$ at a tensile force in $y$-direction of $f_{y}=1 \mathrm{kN}$. (c) Resulting stresses at an equibiaxial tensile loading with $f_{x}=f_{y}=1 \mathrm{kN}$ (blue, red or yellow line). The black lines are $s_{x}$ or $s_{y}$ of (a) and (b). (d) Coupling of forces at an equibiaxial tensile loading with $f_{x}=f_{y}=1 \mathrm{kN}$.

The fit function for the equibiaxially loaded $45^{\circ}$-specimen in Fig. $4 \mathrm{~b}$ is given in Eq. (16). The course of the fit functions $Y^{\mathrm{fit}}(a)$ or $Y_{y}^{\mathrm{fit}}(a)$ was compared with the values of $Y(a)$ or $Y_{y}(a)$ determined for the straight crack paths using Eq. (6) with FE for $k_{i}$, and the exact stresses at the middle of the uncracked specimen $\left(s_{x}=0.062 \mathrm{MPa}\right.$ and $s_{y}=2.933 \mathrm{MPa}$ for PM, $s_{x}=0.0362 \mathrm{MPa}$ and $s_{y}=2.948 \mathrm{MPa}$ for Al6061, cf. section 3.1) for $k_{\infty}$ using Eq. (4). It is shown that the determined fit functions approximate the crack length dependent correction values with a deviation of less than $3 \%$.

$$
\begin{aligned}
& Y_{y}^{\mathrm{fit}}(a)=1.02176-2.94 \cdot 10^{-3} \cdot a+2.02 \cdot 10^{-4} \cdot a^{2}-3.45 \cdot 10^{-6} \cdot a^{3}+3.5 \cdot 10^{-8} \cdot a^{4} \\
& Y^{\mathrm{fit}}(a)=0.973+3.3 \cdot 10^{-3} \cdot a-1.13 \cdot 10^{-3} \cdot a^{2}+1.418 \cdot 10^{-6} \cdot a^{3}
\end{aligned}
$$

The correction functions $Y^{\text {fit }}(a)$ or $Y_{y}^{\text {fit }}(a)$ deviate for small cracks $(a \rightarrow 5 \mathrm{~mm})$ from the value 1.0 for an infinite plate (Eq. (4), see Fig. 4. The limit values of Eqs. (15) and (16) for $a=5 \mathrm{~mm}$ amount to $Y_{y}^{\mathrm{fit}}(a)=1.0117$ and $Y^{\mathrm{fit}}(a)=0.9866$. The reasons for this lies in the influence of the initial hole. The above correction functions agree very well with the handbook-solution [25, p. 239] for a crack emanating from a circular hole of radius $R$ under uniaxial loading $Y_{y}^{\text {fit }}(a)=1.0252$ or equibiaxial loading $Y^{\text {fit }}(a)=0.9855$.

The stress intensity factors $k$, which are calculated with the determined $Y^{\mathrm{fit}}(a)$ or $Y_{y}^{\mathrm{fit}}(a)$ are plotted in Figs. 5a and 5b. The stress intensity factors $k$ obtained from the FE calculation 

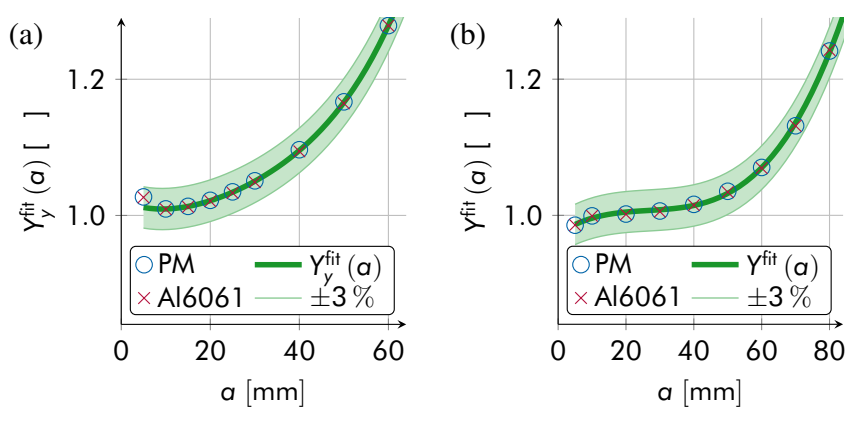

Figure 4. $Y(a)-a$ plot of

(a) $0^{\circ}$-specimen and

(b) $45^{\circ}$-specimen. Comparison

of the solutions for the exact

straight crack path computed

with the determined stresses and thus the corresponding $k_{x}, k_{y}$ and

$k_{\infty}$ for PM (blue dots) and

Al6061(red crosses) with the material independent polynomial

fit (thick green line) and the $\pm 3 \%$ deviation of this fit (thin green lines).

are also shown. The deviation of the $k$ values from the FE calculation with the calculated $k$ values by means of $Y^{\mathrm{fit}}(a)$ or $Y_{y}^{\mathrm{fit}}(a)$ is also below $3 \%$. The comparison of stress intensity factors calculated using $Y^{\text {fit }}(a)$ or $Y_{y}^{\text {fit }}(a)$ with stress intensity factors of real crack paths computed by FE for the crack paths and crack tip coordinates, see Ref. [21] and Figs. 5c and $5 \mathrm{~d}$, also shows deviations of less than $3 \%$. This has shown that it is possible to calculate the stress intensity factors correctly using the correction functions $Y^{\text {fit }}(a)$ for $45^{\circ}$-specimen or $Y_{y}^{\text {fit }}(a)$ for $0^{\circ}$-specimen within minor errors.

(a)
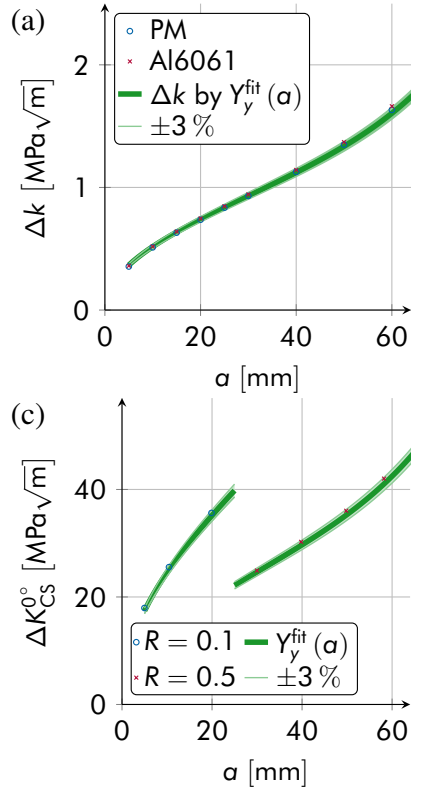

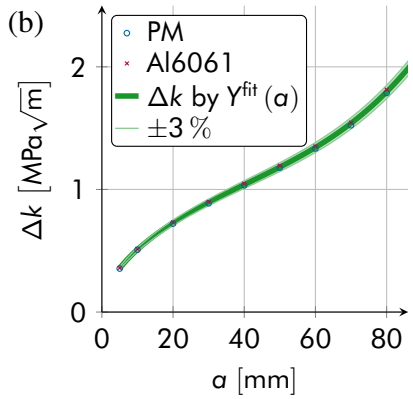

(d)

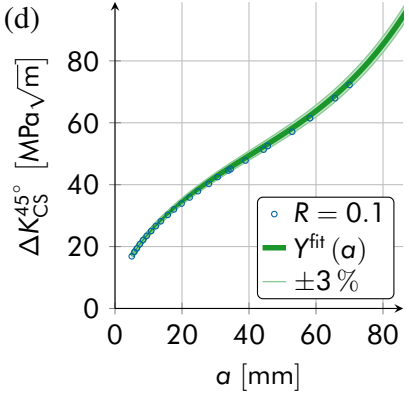

Figure 5. Calculated cyclic stress intensity factors for (a) $0^{\circ}$-specimen and (b) $45^{\circ}$-specimen loaded with unit force. Calculated cyclic stress intensity factors for experimentally determined crack paths resulting from (c) uniaxially loaded $0^{\circ}$-specimen and (d) equibiaxially loaded $45^{\circ}$-specimen.

\section{Summary}

Cruciform specimens with the design by Brown and Miller [10] were examined. It was demonstrated that the coupling of the forces in the measuring area is less than $3 \%$. The determined correction functions $Y^{\mathrm{fit}}(a)$ or $Y_{y}^{\mathrm{fit}}(a)$ approximate the crack length dependent correction values with a deviation of less than $3 \%$. Furthermore, depending on the alignment of the starting notches, a material independent $K$-solution for a straight crack path was found and compared to experimental crack paths for different $R$-ratios. The deviations of the cyclic stress intensity factors were also less than $3 \%$. This means, an easy calculation of $K$ can be done in the proposed manner. 


\section{Acknowledgement}

The authors thank and acknowledge gratefully funding of subprojects B4 and C5 within Collaborative Research Center SFB 799 by German Research Foundation (DFG). In particular, the authors want to thank Stephanie Ackermann for her support in the production of the specimens and Matthias Brensing and Yangxi Qiu for their support during the uniaxial and equibiaxial experiments.

\section{References}

[1] R. Yuuki, K. Akita, N. Kishi, Fatigue Fract. Eng. Mater. Struct. 12, 93 (1989)

[2] H. Kitagawa, R. Yuuki, K. Tohgo, Fatigue Fract. Eng. Mater. Struct. 2, 195 (1979)

[3] V. Shlyannikov, A. Zakharov, Eng. Fract. Mech. 123, 86 (2014)

[4] E. Lee, R. Taylor, Eng. Fract. Mech. 78, 1555 (2011)

[5] S. Mall, V. Perel, Int. J. Fatigue 74, 166 (2015)

[6] H. Misak, V. Perel, V. Sabelkin, S. Mall, Int. J. Fatigue 55, 158 (2013)

[7] V. Shlyannikov, A. Tumanov, A. Zakharov, Theor. Appl. Fract. Mech. 73, 68 (2014)

[8] R. Neerukatti, S. Datta, A. Chattopadhyay, N. Iyyer, N. Phan, Fatigue Fract. Eng. Mater. Struct. 41, 387 (2017)

[9] S. Henkel, D. Holländer, M. Wünsche, H. Theilig, P. Hübner, H. Biermann, S. Mehringer, Eng. Fract. Mech. 77, 2077 (2010)

[10] M.W. Brown, K.J. Miller, in Multiaxial Fatigue (ASTM Int., 1985), pp. 135-153

[11] S. Datta, A. Chattopadhyay, N. Iyyer, N. Phan, Int. J. Fatigue 109, 103 (2018)

[12] A.C. Pickard, The Journal of Strain Analysis for Engineering Design 50, 25 (2014)

[13] M.O. Wang, R.H. Hu, C.F. Qian, J.C.M. Li, Fatigue Fract. Eng. Mater. Struct. 18, 1443 (1995)

[14] S. Henkel, E. Liebelt, H. Biermann, S. Ackermann, Fracture and Structural Integrity 9 , 466 (2015)

[15] C.H. Wolf, S. Henkel, A. Burgold, Y. Qiu, M. Kuna, H. Biermann, Adv. Eng. Mater. (2019), in press, doi:10.1002/adem.201800861

[16] V. Shlyannikov, Eng. Fract. Mech. 108, 3 (2013)

[17] C.D. Donne, K.H. Trautmann, H. Amstutz, in Multiaxial Fatigue and Deformation (ASTM International, 2000), pp. 405-405-18

[18] C.F. Qian, M.O. Wang, B.J. Wu, S.H. Dai, J.C.M. Li, J. Eng. Mater. Technol. 118, 349 (1996)

[19] C.F. Qian, M.O. Wang, B.J. Wu, S.H. Dai, J.C.M. Li, J. Eng. Mater. Technol. 118, 356 (1996)

[20] S. Henkel, C.H. Wolf, A. Burgold, M. Kuna, H. Biermann, Fracture and Structural Integrity 13, 135 (2019)

[21] C.H. Wolf, S. Henkel, A. Burgold, Y. Qiu, M. Kuna, H. Biermann, Int. J. Fatigue 124, 595 (2019)

[22] E. Mönch, D. Galster, Br. J. Appl. Phys. 14, 810 (1963)

[23] A.A. Griffith, Proceedings of the First International Congress for Applied Mechanics pp. 55-63 (1924), Delft

[24] C.D. Donne, Übertragbarkeit von Risswiderstandskurven von Standardproben auf biaxial belastete, bauteilähnliche Kreuzproben (VDI Verlag, 1997)

[25] Y. Murakami, Stress intensity factors handbook (Pergamon Press, 1987) 